\title{
Oxygen sensing and signal transduction in hypoxic pulmonary vasoconstriction
}

\author{
Natascha Sommer, levgen Strielkov, Oleg Pak and Norbert Weissmann \\ Number 11 in the series "Physiology in respiratory medicine" \\ Edited by R. Naeije, D. Chemla, A. Vonk-Noordegraaf and A.T. Dinh-Xuan
}

\begin{abstract}
Affiliation: Excellence Cluster Cardiopulmonary System, University of Giessen Lung Center, German Center for Lung Research (DZL), Justus-Liebig-University, Giessen, Germany.

Correspondence: Norbert Weissmann, Excellence Cluster Cardiopulmonary System, University of Giessen Lung Center, German Center for Lung Research (DZL), Justus-Liebig-University, 35392 Giessen, Germany.

E-mail: Norbert.Weissmanndinnere.med.uni-giessen.de
\end{abstract}

ABSTRACT Hypoxic pulmonary vasoconstriction (HPV), also known as the von Euler-Liljestrand mechanism, is an essential response of the pulmonary vasculature to acute and sustained alveolar hypoxia. During local alveolar hypoxia, HPV matches perfusion to ventilation to maintain optimal arterial oxygenation. In contrast, during global alveolar hypoxia, HPV leads to pulmonary hypertension. The oxygen sensing and signal transduction machinery is located in the pulmonary arterial smooth muscle cells (PASMCs) of the pre-capillary vessels, albeit the physiological response may be modulated in vivo by the endothelium. While factors such as nitric oxide modulate HPV, reactive oxygen species (ROS) have been suggested to act as essential mediators in HPV. ROS may originate from mitochondria and/or NADPH oxidases but the exact oxygen sensing mechanisms, as well as the question of whether increased or decreased ROS cause HPV, are under debate. ROS may induce intracellular calcium increase and subsequent contraction of PASMCs via direct or indirect interactions with protein kinases, phospholipases, sarcoplasmic calcium channels, transient receptor potential channels, voltage-dependent potassium channels and L-type calcium channels, whose relevance may vary under different experimental conditions. Successful identification of factors regulating HPV may allow development of novel therapeutic approaches for conditions of disturbed HPV.

@ERSpublications

ROS originating from mitochondria and/or NADPH oxidases may initiate HPV but exact signalling mechanisms are unclear http://ow.ly/SkaGC

For editorial comments see Eur Respir J 2016; 47: 31-34 [DOI: 10.1183/13993003.01753-2015].

Received: June 162015 | Accepted after revision: Aug 242015 | First published online: Oct 222015

Previous articles in this series: No. 1: Naeije R, Vachiery J-L, Yerly P, et al. The transpulmonary pressure gradient for the diagnosis of pulmonary vascular diseases. Eur Respir J 2013; 41: 217-223. No. 2: Hughes JMB, van der Lee I. The $T \mathrm{~L}, \mathrm{NO} / \mathrm{T} \mathrm{L}, \mathrm{CO}$ ratio in pulmonary function test interpretation. Eur Respir J 2013; 41: 453-461. No. 3: Vonk-Noordegraaf A, Westerhof N. Describing right ventricular function. Eur Respir J 2013; 41: 1419-1423. No. 4: Hamzaoui O, Monnet X, Teboul J-L. Pulsus paradoxus. Eur Respir J 2013; 42: 1696-1705. No. 5: Prisk GK. Microgravity and the respiratory system. Eur Respir J 2014; 43: 1459-1471. No. 6: Dempsey JA, Smith CA. Pathophysiology of human ventilatory control. Eur Respir J 2014; 44: 495-512. No. 7: Petersson J, Glenny RW. Gas exchange and ventilation-perfusion relationships in the lung. Eur Respir J 2014; 44: 1023-1041. No. 8: Wagner PD. The physiological basis of pulmonary gas exchange: implications for clinical interpretation of arterial blood gases. Eur Respir J 2015; 45: 227-243. No. 9: Robertson HT. Dead space: the physiology of wasted ventilation. Eur Respir J 2015; 45: 1704-1716. No. 10: Chemla D, Lau EMT, Papelier Y, et al. Pulmonary vascular resistance and compliance relationship in pulmonary hypertension. Eur Respir J 2015; 46: 1178-1189.

Conflict of interest: None declared.

Copyright OERS 2016 


\section{Hypoxic pulmonary vasoconstriction optimises ventilation-perfusion matching}

Hypoxic pulmonary vasoconstriction (HPV), also known as the von Euler-Liljestrand mechanism, is an intrinsic mechanism of the pulmonary vasculature in response to alveolar hypoxia, to match ventilation to perfusion and optimise pulmonary gas exchange (figure 1). Humans and almost all vertebrates, including mammals [1-4], birds [5], amphibia [6], reptiles [7] and probably even fish [8, 9], depend on this mechanism acting in seconds to divert blood flow from poorly ventilated to well ventilated alveoli.

Under conditions of compromised HPV, such as occurs during anaesthesia $[10,11]$ or pulmonary inflammation (e.g. acute respiratory distress syndrome [12]), or in hepatopulmonary syndrome [13], intrapulmonary shunt flow results in decreased oxygenation of the pulmonary venous blood, systemic arterial hypoxaemia and organ hypoxia. Although beneficial on a short-term local basis, HPV can become detrimental when activated globally in the lung on a sustained basis. Under these conditions, HPV can increase pulmonary vascular resistance and subsequently right heart afterload and may lead, in concert with pulmonary vascular remodelling processes, to fixed pulmonary hypertension and right heart insufficiency. This situation may occur at high altitude or during respiratory diseases, including chronic obstructive pulmonary disease, sleep apnoea and fibrosis, and during failure of ventilation due to neurological diseases. Although HPV was described decades ago, the underlying oxygen sensing and signal transduction mechanisms remain obscure. Research may be complicated by the fact that the acute phase of HPV, which lasts seconds to minutes to match ventilation to perfusion on a breath-to-breath basis, in contrast to sustained HPV, which lasts minutes to hours, may result from different cellular pathways. Understanding HPV may help us to develop therapeutic strategies for impaired gas exchange due to attenuated HPV, as well as for pulmonary hypertension due to generalised HPV. This review aims to provide a summarised overview of the most important clearly established pathways, as well as novel components that are essential and specific for the response of pulmonary vessels to acute and sustained hypoxia leading to vasoconstriction. For a more detailed description of essential and modulatory mechanisms of HPV and their clinical significance we recommend reading the comprehensive review of SYLVESTER et al. [14].

\section{Characteristics of HPV}

Vasoconstriction in response to hypoxia is a unique response exhibited by the post-natal lung and the placenta, both organs that serve for oxygen uptake and thus aim to optimise gas exchange at the air-blood or blood-blood interface, respectively. In contrast, systemic vessels distribute oxygen to peripheral organs and react to tissue hypoxia with vasodilation. Before birth, pulmonary vessels are strongly constricted, hindering blood flow through the nonfunctional lung. After birth, alveolar inflation and oxygenation result in pulmonary vasodilation; thus, from an ontogenic point of view, the HPV phenomenon also may be termed "normoxic pulmonary vasodilation" [15].

The first description of HPV is more than 100 years old, when BRADFORD and DEAN [16], as well as Plumier [17], described in 1894 and 1904, respectively, an increase in pulmonary arterial pressure in response to asphyxia. Later, vON Euler and Liljestrand [18] suggested in 1946 that HPV serves for ventilation-perfusion matching in response to alveolar hypoxia. Shortly thereafter, in 1947, HPV was demonstrated to be also present in humans $[19,20]$. Some decades ago, it became clear that HPV is primarily achieved by vasoconstriction of the pre-capillary pulmonary vessels, located at the entrance of the acinus, and to a lesser degree by post-capillary-located venules [21-24]. These vessels respond mainly
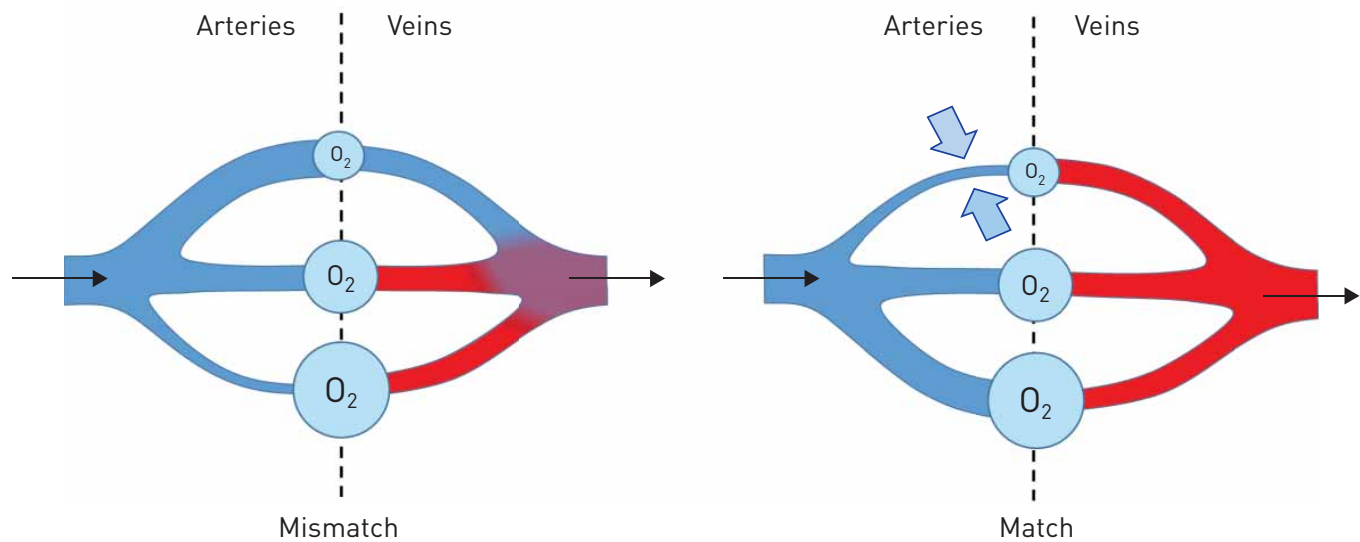

FIGURE 1 Hypoxic pulmonary vasoconstriction optimises gas exchange by matching perfusion to ventilation. Blue arrows indicate the constriction of pulmonary arteries, black arrows the direction of blood flow. 
to alveolar hypoxia, as well as to a drop in pulmonary arterial oxygen tension $\left(P_{\mathrm{O}_{2}}\right)$ [25], but not to changes in pulmonary venous $\mathrm{PO}_{2}$ [26]. When pre-capillary vessels are isolated and endothelium denuded, they constrict in the presence of hypoxia, suggesting that the sensor and effector mechanisms of HPV are located in these vessels [27]. Later, it was demonstrated that isolated pulmonary arterial smooth muscle cells (PASMCs) from the pre-capillary vessels constrict in response to hypoxic exposure [28, 29] or react with an intracellular calcium increase to hypoxia, which is thought to be an essential effector mechanism and thus a cellular surrogate for HPV [30, 31]. In contrast, smooth muscle cells (SMCs) from isolated cerebral arteries dilate during hypoxic exposure [29]. Thus, the essential machinery to induce and execute HPV was thought to be located in PASMCs. Although the trigger mechanism of HPV thus seemed to be intrinsic to PASMCs and is independent from systemic neural [32] or humoral [33, 34] factors, HPV can be modulated by extrinsic factors, such as the nervous system [35, 36], endothelial factors (e.g. nitric oxide) [37-39], circulating hormones [40, 41], volatile agents (e.g. carbon monoxide) [42], metabolism (e.g. $\mathrm{pH}$ ) [43], physical influence (e.g. blood viscosity) [44], sex [40], hypoxia-inducible factor (HIF) [45], endocannabinoid anandamide [46] or arachidonic acid metabolites [47], which might be particularly relevant under physiological and pathological conditions in vivo. An overview of the reactions of lungs in vivo and ex vivo, as well as pulmonary arteries and PASMCs, during exposure to acute and sustained hypoxia is given in figures 2 and 3.

However, the view that PASMCs are the exclusive effector and sensor cell type of HPV is challenged by the concept that pre-conditioning is essential for PASMCs to execute HPV, as in some preparations, isolated vessels only constricted in the presence of endothelium [51, 52]. This pre-conditioning might be particularly true for sustained HPV. Interpretation of these studies, however, is complicated by the facts that the kinetics of HPV in the presence of prolonged hypoxia depend on the experimental setting, the differentiation between acute and prolonged hypoxia is not well defined and both phases may overlap [50, 53-56]. Recently, it was shown by real-time in vivo fluorescence measurements that hypoxic ventilation in the isolated ventilated lung caused endothelial membrane depolarisation in alveolar capillaries that propagated to upstream arterioles in a connexin-40-dependent manner and that this signal, as well as HPV (but not angiotensin-II-induced vasoconstriction), was attenuated during pharmacological or genetic inhibition of connexin 40 [57]. As connexin 40 is exclusively expressed in endothelial cells, this study challenged the hitherto widely accepted model of PASMCs being the oxygen sensor and effector cell type [57]. However, this study also illustrates the difficulties of defining acute and prolonged hypoxic response, as HPV was determined after 10 min of hypoxic ventilation, which might not reflect acute HPV under other experimental conditions where the maximum is reached within $5 \mathrm{~min}$ of hypoxia $[1,2]$. Moreover, HPV was decreased during connexin 40 inhibition to about $30 \%$ of the response in wild-type mice, but not completely inhibited, which points to a sensitising or modulating role of the endothelium.

Even if in vivo some pre-conditioning by other cell types, e.g. the endothelium, is necessary, PASMCs seem to contain all essential components for the oxygen sensing and signal transduction pathway leading to HPV, as acute HPV could be detected in isolated PASMCs in the absence of endothelium, as previously outlined [28-30].

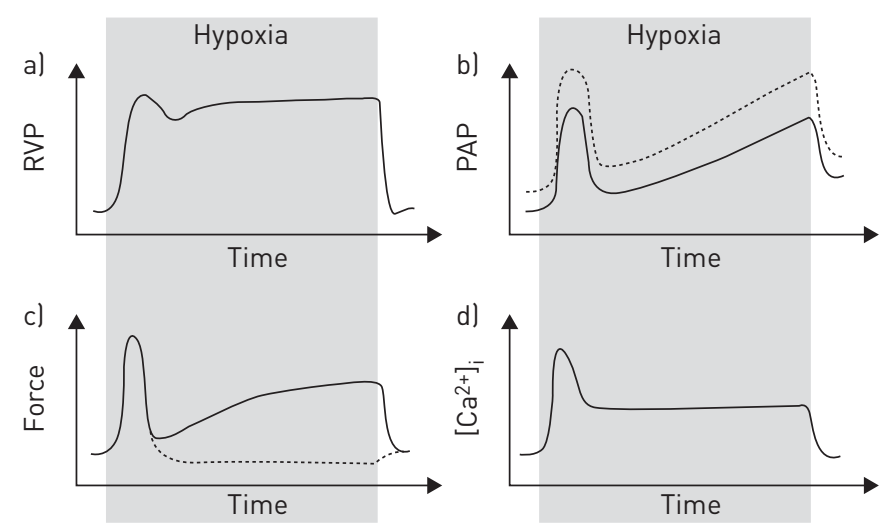

FIGURE 2 Schematic representation of typical responses to hypoxia observed in vivo and in vitro. a) Changes in right ventricular pressure (RVP) in vivo [48]. b) Changes in pulmonary artery pressure (PAP) in isolated lungs $[38,49]$. The dashed line shows the effect of nitric oxide synthase inhibition. c) Changes in contractile force in isolated intrapulmonary arteries [50]. The dashed line shows the effect of removed endothelium. d) Changes in intracellular calcium concentration $\left(\left[\mathrm{Ca}^{2+}\right]_{i}\right)$ in isolated intrapulmonary arteries [50]. For each graph, the duration of hypoxia is $\geqslant 40 \mathrm{~min}$. 


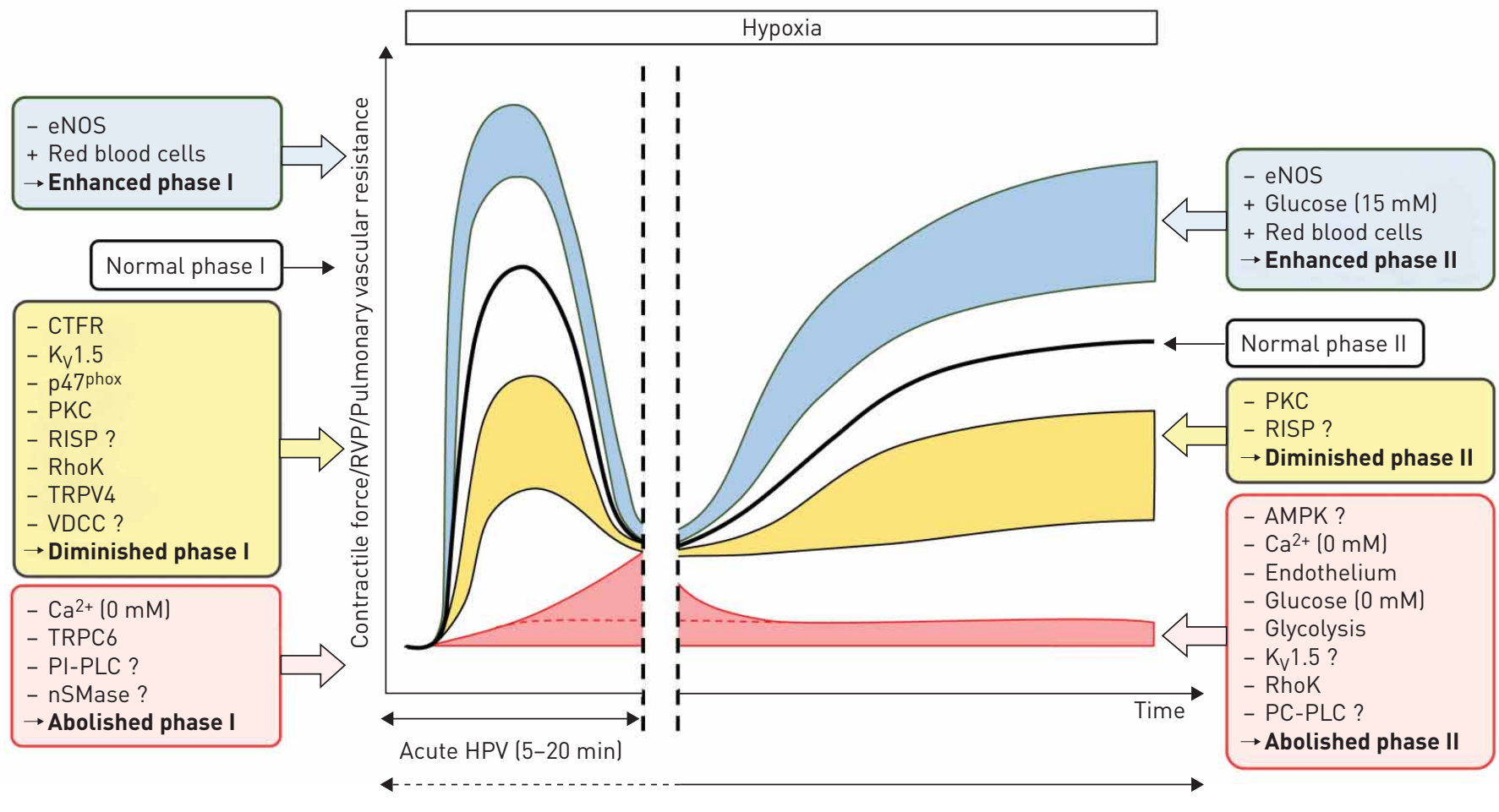

Sustained HPV ( $\geqslant 180 \mathrm{~min})$

FIGURE 3 Major factors contributing to hypoxic pulmonary vasoconstriction (HPV). Factors are only depicted for which the importance for HPV or hypoxia-induced contractions has been shown in intact lung experiments or the isolated pulmonary artery, respectively. For factors that are labelled with a question mark, either specificity for HPV has not been shown or conflicting results were reported. The potential role of reactive oxygen species and mitochondria is depicted in figure 4. Minus signs indicate the inhibition or removal of a factor, while plus signs indicate addition. For details and further factors (extrinsic and intrinsic to pulmonary arterial smooth muscle cells) that modulate HPV, see main text. AMPK: adenosine monophosphate-activated protein kinase; CFTR: cystic fibrosis transmembrane conductance regulator; eNOS: endothelial nitric oxide synthase; $\mathrm{K}_{\mathrm{v}}$ : voltage-dependent potassium channel; nSMase: neutral sphingomyelinase; PKC: protein kinase C; PI-PLC: phosphatidylinositol-specific phospholipase C; PC-PLC: phosphatidylcholine-specific phospholipase C; p47 phox: 47-kDa cytosolic subunit of the NADPH oxidase; RISP: Rieske iron-sulfur protein; RhoK: Rho-kinase; RVP: right ventricular pressure; TRPC6: transient receptor potential canonical channel type 6; TRPV4: transient receptor potential vanilloid channel type 4; VDCC: voltage-dependent calcium channels.

\section{Trigger mechanism for HPV: mitochondrial reactive oxygen species}

For decades the quest for the main mediator triggering the intracellular calcium increase in PASMCs that precedes HPV remained a central question. Intracellular calcium increase, resulting in myosin light chain phosphorylation and contraction, is essential in HPV signalling $[14,55,58]$, although the involvement of an endothelium-dependent or -independent rho-kinase activation that could induce sensitisation by inhibition of the myosin light chain phosphatase during acute HPV is under debate [59]. Thus, upstream signalling mechanisms that induce intracellular calcium increase were searched for.

As force development is largely dependent on energy production, initial studies suggested inhibition of mitochondrial ATP production, which is an oxygen-dependent process, as a sensor mechanism. However, only some mitochondrial inhibitors prevented HPV in early setups [60-63] and HPV occurs at oxygen concentrations that are thought to be way above the oxygen sensitivity of mitochondria. In the isolated, buffer-perfused lung, a $\mathrm{PO}_{2}$ below $40-75 \mathrm{mmHg}$ in the ventilated air $[2,64]$ and in $\mathrm{PASMCs}$ a $\mathrm{PO}_{2}$ of $25-50 \mathrm{mmHg}$ in the buffer $[28,29]$ was sufficient to induce contraction, while only a very small inhibition of mitochondria, well below the limit for substantial reduction of ATP production, was detected in these $\mathrm{PO}_{2}$ ranges in isolated lungs and PASMCs [64]. Moreover, no ATP depletion was measured during acute hypoxia in the whole lung $[65,66]$, although this finding could also be caused by upregulation of glycolytic ATP production [67]. This mechanism may be of particular importance for sustained HPV, which has been shown to be dependent on anaerobic glycolysis [50].

However, for acute HPV, some mechanism acting independently of energy deprivation at mild hypoxia was searched for. Additionally, the signalling mechanism, at least for acute HPV, is required to be very fast, as HPV adapts ventilation to perfusion in seconds on a breath-to-breath basis [2]. Subsequently, a different oxygen-dependent mediator came into the spotlight: reactive oxygen species (ROS). This is actually the general term for different molecules including, for example, the short-lived superoxide, which cannot move 


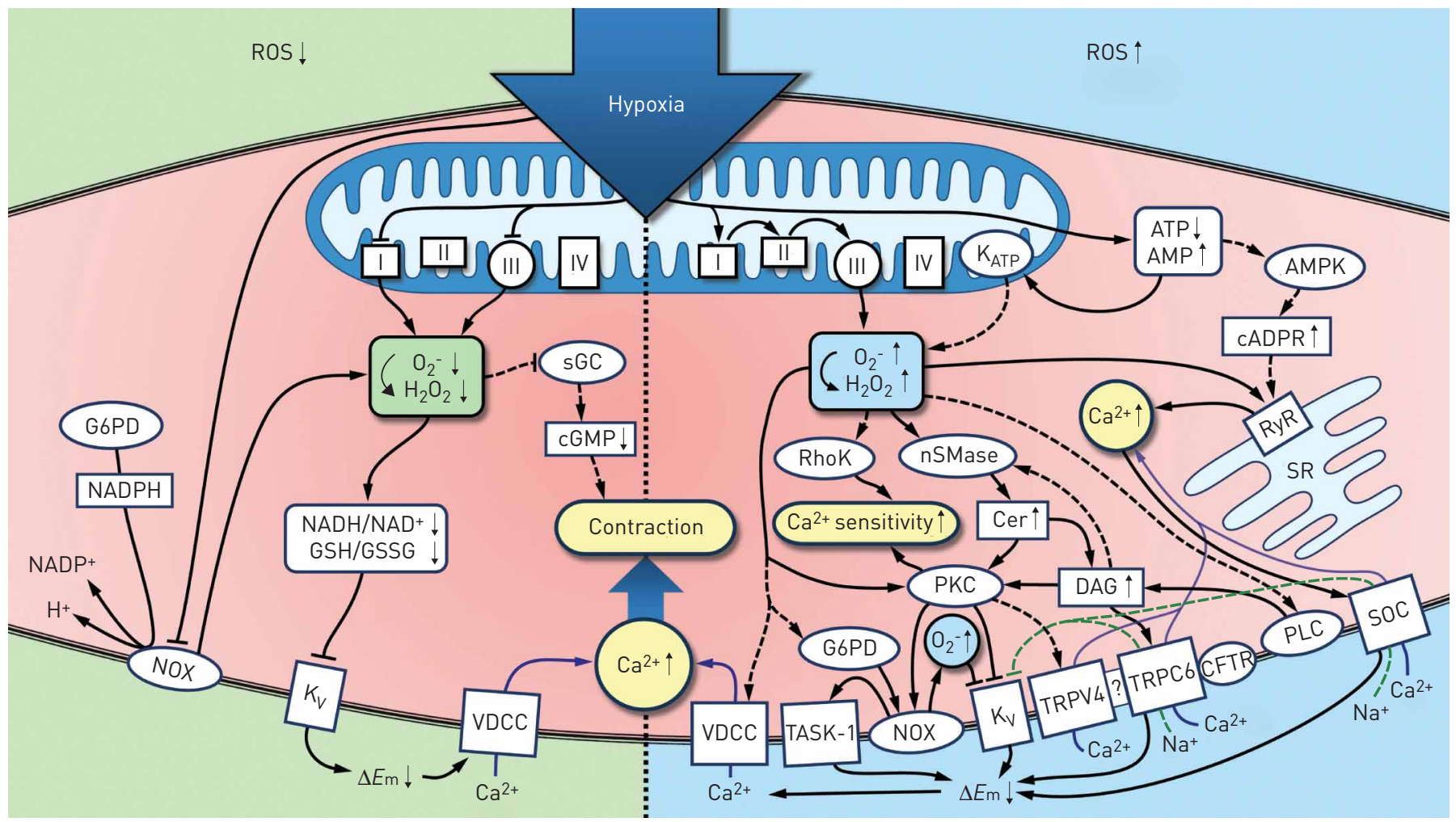

FIGURE 4 Current concepts suggesting decreased or increased reactive oxygen species (ROS) production during hypoxia as a trigger for hypoxic pulmonary vasoconstriction (HPV). Solid lines indicate pathways that have been reported to be involved in HPV or hypoxia-induced responses on the cellular level. Dashed lines indicate hypothetical pathways. Lines ending with arrows indicate a stimulatory effect, whereas lines ending with a cross bar indicate inhibitory effect. For details see main text. AMPK: adenosine monophosphate-activated protein kinase; cADPR: cyclic adenosine diphosphoribose; Cer: ceramide; cGMP: cyclic guanosine monophosphate; CFTR: cystic fibrosis transmembrane conductance regulator; DAG: diacylglycerol; $\triangle \mathrm{Em}$ : cellular membrane potential; G6PD: glucose-6-phosphate dehydrogenase; GSH: reduced glutathione; GSSG: oxidised glutathione; $K_{\text {ATP: }}$ ATP-dependent potassium channel; $\mathrm{K}_{\mathrm{V}}$ : voltage-dependent potassium channel; NOX: NADPH oxidase; nSMase: neutral sphingomyelinase; PKC: protein kinase C; PLC: phospholipase C; RhoK: Rho-kinase; RyR: ryanodine receptor; sGC: soluble guanylate cyclase; SR: sarcoplasmic reticulum; SOC: store-operated channel (e.g. acid-sensing ion channel 1); TASK-1: Twik-related acid-sensitive $\mathrm{K}^{+}$channel, subtype 1; TRPC6: transient receptor potential canonical channel type 6; TRPV4: transient receptor potential vanilloid channel type 4; VDCC: voltage-dependent calcium channels.

freely across membranes but is metabolised to membrane-diffusible $\mathrm{H}_{2} \mathrm{O}_{2}$ by superoxide dismutases (SODs). Besides acting directly at calcium channels, ROS can influence the cellular redox state, which is characterised by the ratio of oxidised to reduced proteins, e.g. oxidised to reduced glutathione (GSSG/GSH) or oxidised to reduced nicotinamide adenine dinucleotide (NAD/NADH). As mitochondria are the main ROS-producing sites, and ROS production is thought to be an oxygen-dependent process, ROS or the cellular redox state seemed to be ideal as a fast-acting mediator of HPV. Thus initially, the so-called "redox hypothesis" of HPV was formulated, which defines the shift to a more reduced cellular redox state acting as trigger mechanism for acute HPV. However, in view of conflicting results regarding ROS measurements and based on different mitochondrial inhibitor studies, two opposing hypotheses are still under debate: 1) the original redox hypothesis, favouring a decrease of ROS released by mitochondria triggering HPV, and 2) an increase of mitochondrial ROS release during hypoxia (figure 4; for review see [68-72]).

\section{Decreased mitochondrial ROS release as a trigger for HPV}

The original redox hypothesis was based on the observation that inhibition of mitochondrial complexes I and III inhibited HPV in isolated lungs, pulmonary arteries and PASMCs, caused vasoconstriction during normoxia and decreased mitochondrial ROS production, as did hypoxia. Thus, inhibition of complexes I and III was proposed to mimic the hypoxic ROS decrease, cause vasoconstriction in normoxia and subsequently inhibit further hypoxic vasoconstriction, as ROS cannot further decrease [73]. Although inhibition of complex IV by cyanide also caused normoxic vasoconstriction, it increased ROS production and did not cause inhibition of HPV, suggesting that ROS release was not causative for HPV. However, the experiments did not take into account that ROS could further increase in hypoxia after cyanide application $[73,74]$. Downstream of mitochondrial ROS release, potassium channels were suggested to link the altered redox state to L-type calcium channels. As it was discovered very early that inhibitors of L-type calcium 
channels decrease HPV, the paradigm was developed that HPV was primarily caused by activation of L-type calcium channels via cellular membrane depolarisation caused by potassium channel inhibition [75].

Along these lines, the initial redox hypothesis claimed that redox-sensitive cysteine bridges of potassium channels were the targets for the altered intracellular redox state (defined by redox couples like GSH/GSSG and NADH/NAD) caused by decreased mitochondrial ROS release [73, 76]. Redox modification of potassium channels could lead to their inhibition, cellular membrane depolarisation and activation of L-type calcium channels [77-79]. Indeed, specific potassium channels in PASMCs, particularly the voltage-gated potassium $\left(\mathrm{K}_{\mathrm{V}}\right)$ channels, $\mathrm{K}_{\mathrm{V}} 2.1, \mathrm{~K}_{\mathrm{V}} 1.5$ and $\mathrm{K}_{\mathrm{V}} 9.3$ [80-82], were inhibited by hypoxia and/ or reducing agents $[83,84]$. Recently, mitochondria in PASMCs have been shown to be located closer to the plasmalemmal membrane than in SMCs of the mesenteric artery, which might explain the more potent effect of mitochondrial inhibitors on potassium currents in PASMCs [85]. Different potassium channels may contribute to the hypoxic response, as animals only deficient for $\mathrm{K}_{\mathrm{V}} 1.5$ channels showed only a partial inhibition of HPV [86].

Measurement of ROS during hypoxia has turned out to be enormously difficult and prone to artefacts due to nonspecificity and autoxidation of fluorescent ROS probes, accidental re-oxygenation during the measurement procedure, time dependency of ROS release and detoxification, as well as extra- and intracellular compartmentalisation of ROS production [87-90]. In this regard, measurement of ROS at the whole lung level revealed a decrease of ROS concentration during acute hypoxia, while ROS detection on cellular levels mostly showed increased ROS levels [87]. Thus a compartmentalised ROS release may underlie HPV. This hypothesis is supported by a study that showed increased ROS production in the whole lung during hypoxia when some of the ROS-generating systems were blocked [91].

\section{Increased mitochondrial ROS release as a trigger for HPV}

In the face of the conflicting results with regard to ROS determination, meanwhile, an opposing scenario has evolved, based on investigations that showed increased hypoxic ROS production originating from mitochondria $[60,70]$. This scenario proposes that ROS release into the mitochondrial membrane space at the outer ubiquinol-binding site of the mitochondrial complex III triggers HPV. This hypothesis was based on results showing that inhibition of complex I and proximal parts of complex III inhibited mitochondrial hypoxic ROS production and cellular hypoxic responses, while distal inhibition at complex III and complex IV did not interfere with or enhance hypoxic responses. Bypassing the inhibition of complex I by the complex II substrate succinate restored hypoxia-induced effects [50]. However, nonspecificity of some of the applied inhibitors, as well as of some of the observed effects, limits the interpretation of mitochondrial inhibitor studies [87].

More recently, additional evidence has accumulated that indeed a paradoxical increase of ROS might trigger HPV. Fluorescent dyes, like MitoSOX (Molecular Probes, Invitrogen, Paisley, UK), targeted to the mitochondria, showed increased mitochondrial ROS production [64]. Newly developed, targeted intracellular ROS/redox probes based on genetically modified fluorescent proteins have been used in an attempt to overcome the limitations of fluorescent dyes; however, they also mostly cannot distinguish between different ROS species. The most advanced investigation in this regard, occurring $>20$ years after the initial redox hypothesis, proposes that mitochondrial matrix ROS is unchanged and ROS in the inner membrane space of mitochondria and cytosol is increased in PASMCs during hypoxia, albeit cytosolic ROS increase was not specific for PASMCs as it was also increased in aortic SMCs during hypoxia [90]. The same reduction-oxidation-sensitive green fluorescent protein (roGFP) was also applied in lung slices superfused with hypoxia media, which also showed oxidation of the probe [92].

Inhibitors of different ROS species were used to try to shed light onto the role of ROS in HPV. However, concentration- and time-dependent variations, as well as lack of specificity for HPV, obscure the relevance of the observations. Oxidants like $\mathrm{H}_{2} \mathrm{O}_{2}$ caused pulmonary vasoconstriction during normoxia in isolated lungs [93, 94], but antioxidants also caused constriction of isolated pulmonary vessels [95]. A more recent investigation showed biphasic constriction of the pulmonary artery by application of $\mathrm{H}_{2} \mathrm{O}_{2}$ that resembled properties of the hypoxic response with regard to its response to different inhibitors [96]. Moreover, oxidants $[94,95,97]$ as well as antioxidants $[60,98]$ inhibited HPV. This finding might be due to the fact that these substances can cause both activation and inhibition of ion channel activity under different conditions [99]. Additionally, these agents may exert a nonspecific vasodilatory effect on the pulmonary vasculature, as shown for $\mathrm{H}_{2} \mathrm{O}_{2}$ [94] or tempol (4-hydroxy-2,2,6,6-tetramethylpiperidine 1-oxyl) [98]. In this regard it is important to point out that nonspecific effects of vasoactive substances on the contractile machinery of the cell should be distinguished from specific effects acting on HPV by testing the substances' vasoactivity in the presence of nonspecific vasoconstrictors like angiotensin, potassium chloride or the thromboxane mimetic U46619. Detailed pharmacological interventions in this regard were employed in the isolated lung to interfere with the release of superoxide or $\mathrm{H}_{2} \mathrm{O}_{2}$ and only the 
cell-permeable superoxide scavenger nitro blue tetrazolium (NBT) inhibited HPV specifically [100]. As NBT did not increase basal normoxic pulmonary arterial pressure, it was concluded that an increase rather than a decrease of superoxide triggers HPV [100]. In contrast, lucigenin measurements provided evidence for a decrease of superoxide occurring in hypoxia in the isolated lung [101]. With regard to defining the role of superoxide versus $\mathrm{H}_{2} \mathrm{O}_{2}$ on the cellular level, the effect of decreasing $\mathrm{H}_{2} \mathrm{O}_{2}$ by catalases, or decreasing superoxide but increasing $\mathrm{H}_{2} \mathrm{O}_{2}$ by mitochondrial matrix-located manganese SOD (MnSOD or SOD2) was tested in PASMCs [102]. Interestingly, MnSOD augmented hypoxia-induced calcium release, while catalases attenuated it, suggesting that increased $\mathrm{H}_{2} \mathrm{O}_{2}$ release induced by mitochondrial matrix superoxide contributes to hypoxia-induced calcium release [102]. These data are in accordance with studies showing increased mitochondrial matrix superoxide concentration in hypoxia by the fluorescent dye MitoSOX, which preferentially detects superoxide in the mitochondrial matrix [64], but may be in conflict with studies employing the mitochondrial matrix-targeted roGFP that showed unchanged mitochondrial matrix redox state in hypoxia [90]. Independent of the uncertainty regarding the role of mitochondrial matrix superoxide, in further support of the hypothesis that increased intracellular $\mathrm{H}_{2} \mathrm{O}_{2}$ triggers HPV, it was shown that enhanced ROS removal by glutathione peroxidase 1 or catalase overexpression inhibited the acute hypoxic response in freshly isolated mouse PASMCs [103]. Furthermore, catalase overexpression or application of a SOD-catalase mimetic inhibited the hypoxia-induced calcium increase in lung slices [92]. In an interesting approach, the role of physiological ROS production was tested by inducing an NADPH-oxidase-dependent oxidative burst in macrophages, which stimulated the contraction of small pulmonary arteries [104]. Nonspecific effects of certain inhibitors may be explained by the finding that, on the vessel or whole organ level, pre-conditioning of the endothelium may influence results, because in non-preconstricted arteries only sustained HPV, but not acute HPV, was inhibited by the antioxidants ebselen and tempol [56]. In summary, evidence is accumulating that indeed an intracellular increase of $\mathrm{H}_{2} \mathrm{O}_{2}$ in PASMCs caused by increased mitochondrial superoxide production or release causes hypoxic responses that are intrinsic to PASMCs.

\section{Potential mechanisms of increased hypoxic mitochondrial ROS release}

Although evidence for a paradoxical increase of mitochondrial ROS release during hypoxia is accumulating, it remains unclear how increased ROS levels are achieved. While the redox hypothesis is driven by the fact that the decrease in ROS levels can be easily explained by decreased substrate (oxygen) availability, the increase of ROS during hypoxia seems counter-intuitive. Generally, some factors favour ROS release from mitochondria: increased lifetime of ubisemiquinone [105], electron backflow through complex II [106], mitochondrial calcium influx [107], activation of mitochondrial potassium channels [108] or mitochondrial hyperpolarisation [109]. While some of the above factors seem unlikely to contribute to HPV, some have indeed been observed in hypoxia.

Recently, the potential ROS-releasing site at complex III was directly targeted by genetic manipulation of the Rieske iron-sulfur protein (RISP), which transfers one electron from ubiquinol at the outer ubiquinol-binding site to cytochrome $\mathrm{c}$ thereby producing ubisemiquinone, which transfers the second electron to cytochrome $\mathrm{b}$ of complex III but is also prone to release the electron instead to molecular oxygen to create superoxide. Knock-down or overexpression of RISP inhibited or increased, respectively, the hypoxia-induced increase of ROS and calcium in cells, mitochondria and complex III isolated from PASMCs [110]. Pulmonary arteries of lung slices from mice with an inducible smooth muscle-specific depletion of the RISP lacked hypoxia-induced increases of calcium and these mice showed an attenuated increase in right ventricular systolic pressure in response to hypoxia, suggesting that indeed hypoxic ROS release from the outer ubiquinol-binding site results in HPV [111]. However, these studies are limited by the fact that RISP depletion will also alter electron transfer downstream of cytochrome $\mathrm{c}$ and thereby limit physiological functions regulated by mitochondrial respiration. Although there are no respiration measurements for the RISP-deficient cells, a limitation of mitochondrial function can be assumed, as the mitochondrial membrane potential of these cells was decreased [111]. It was suggested that ROS production at RISP could be increased in hypoxia by a small inhibition of the respiratory chain with concomitant prominent hypoxic cytochrome $\mathrm{c}$ reduction, leading to increased electron availability at complex III, thereby possibly increasing the lifetime of ubisemiquinone and ROS production at the outer ubiquinol-binding site of complex III [112]. Indeed, a small inhibition of the respiratory chain, as well as cytochrome c reduction, was detected in PASMCs in the range of the $\mathrm{PO}_{2}$ in which PASMCs react to hypoxia. However, these alterations were not specific for PASMCs as they were also detected in other SMCs [64]. It also has yet to be clarified how increased electron availability at complex III via increased cytochrome $\mathrm{c}$ reduction can induce ROS production at the outer ubiquinol-binding site. It is generally accepted that simple inhibition of complex IV and electron backup is not sufficient for ROS production at the outer ubiquinol-binding site of complex III [109], as reduced cytochrome c cannot dock to RISP and thus prevents electron transfer from ubiquinol and production of ubisemiquinone [113]. Furthermore, this concept contradicts the observation that complex IV inhibition by cyanide does not inhibit 
HPV $[60,73]$. Therefore, inhibition of complex IV seems to require an additional mechanism to induce ROS production at complex III. Additional damage of the ubiquinol-binding site and RISP protein, e.g. by ischaemia, has been suggested to result in increased electron leak at this site [113] and also direct interference of complex III with oxygen, which is enriched in the inner mitochondrial membrane, thereby possibly altering the structure and/or function of complex III during hypoxia [112].

Additional factors favouring ROS production at complex III need to be looked for in the future. Interestingly, increased mitochondrial membrane potential was found during hypoxia in PASMCs [64, 74], which is a condition that strongly favours ROS production at complex III [109]. However, the relevance of mitochondrial hyperpolarisation and its upstream mechanism remain unclear.

Moreover, ROS production by reverse electron transfer in complex II cannot be excluded as a mechanism for ROS production, as the hypoxic response was detectable in pre-acinar arteries but absent from intra-acinar arteries of mice with mutant succinate dehydrogenase complex subunit $\mathrm{D}\left(\mathrm{SDHD}^{+/-}\right.$mice), which is a subunit of complex II [114].

\section{NADPH oxidases as ROS sources}

While early studies employing mitochondrial inhibitors and PASMCs deficient of mitochondria suggested an essential role of mitochondria for HPV [60, 61, 73], the search for the HPV mechanism was extended to other oxygen-sensitive cellular processes. One of these processes is ROS production by NADPH oxidases [91, 115, 116]. MARSHALl et al. [115] first described a NADPH oxidase in pulmonary arteries and isolated PASMCs and their data suggested increased superoxide production by this NADPH oxidase under hypoxic conditions. In contrast to the, at that time, well characterised phagocytic NADPH oxidase, which produces ROS for bacterial defence and showed a hyperbolic decrease of superoxide production in response to decreased $\mathrm{PO}_{2}$ [117], a non-phagocytic NADPH oxidase did increase ROS production during hypoxia when additionally stimulated by the protein kinase $\mathrm{C}$ (PKC) activator phorbol 12-myristate 13-acetate [118]. Thus, the paradoxical increase in ROS production during hypoxia might be explained by increased activation of a non-phagocytic NADPH oxidase during mild hypoxia, when oxygen availability suppresses superoxide production only minimally [118]. PKCs have long been suggested to regulate HPV via NADPH oxidase activation [119], although they have many alternative targets that may affect HPV [120]. In this regard, it was suggested that ROS release from mitochondria activates PKCE, which in turn activates NADPH oxidase to enhance ROS production and leads to a calcium increase [121]. Recently, PKC $\xi$-dependent NADPH oxidase activation has been suggested to be induced by increased ceramide levels due to mitochondrial-dependent activation of neutral sphingomyelinase (nSMase) [122-125]. However, inhibition of the nSMase also decreased U46619-induced vasoconstriction in pulmonary arteries [122]. In line with the notion that non-phagocytic NADPH oxidases may transfer hypoxic responses, genetic studies showed that deletion of the gp91 subunit of the phagocytic NADPH oxidase did not affect HPV [126]. However, deletion of the subunit p47, which is also part of non-phagocytic NADPH oxidases located in endothelium-denuded mouse pulmonary arteries [121], caused a specific reduction of acute HPV but unchanged sustained HPV [118]. Moreover, acute hypoxia caused an increase of NADPH oxidase activity and translocation of p47 from the cytosol to the plasma membrane [121]. The NADPH oxidase containing Nox4 (NADPH oxidase 4) as a substitute for gp91 [127], which is expressed in mouse [128], lamb [129] and human lungs [130], might be of particular importance in HPV [131]. Nox4-derived increase in ROS production induced $\mathrm{K}_{\mathrm{V}}$ channel current inhibition and may thus initiate HPV [116]. Moreover, it has been suggested that Nox4 transfers the oxygen-sensing mechanism via interaction with the two-pore domain potassium channel TASK-1 (Twik-related acid-sensitive $\mathrm{K}^{+}$channel, subtype 1 ) in HEK293 cells [132]. Together with other potassium channels, TASK-1 controls the low resting tone of pulmonary arteries and is blocked by moderate hypoxia [133]. In human pulmonary arteries, TASK-1 activity, whose active phosphorylated state was decreased by hypoxia [134], was regulated by the Src family tyrosine kinase and thus may provide a mechanism for hypoxia-induced membrane depolarisation. Independent from a possible link of NADPH oxidases to TASK-1, the final demonstration of the importance of NADPH oxidases and specifically Nox4 in HPV is missing. Inhibition of NADPH oxidase in general by inhibitors like diphenylene iodonium (DPI), apocynin, cadmium sulfate or 4-(2-aminoethyl) benzenesulfonyl fluoride inhibited HPV in isolated lungs or pulmonary arteries [135-137]. As application of inhibitors did not induce pulmonary vasoconstriction in normoxia, it was concluded that an increase rather than a decrease of superoxide release by NADPH oxidases induced HPV [138]. However, these studies do not prove an essential role for NADPH oxidases, as most of these inhibitors either act nonspecifically (as in the case of DPI) or inhibit not only HPV but also nonspecific vasoconstriction (as in the case of apocynin). Recently, the new NADPH oxidase inhibitor VAS2870 was shown to decrease HPV in pulmonary arteries but not completely inhibit HPV [124]. Moreover, application of VAS2870 did not influence the hypoxic response in pulmonary arteries without pre-tone [56]. Interpretation of experiments with NADPH oxidase inhibitors in isolated lungs are limited by the possible presence of leukocytes that 
have migrated into the tissue despite buffer perfusion. In this regard, it was recently shown that macrophages can influence HPV in isolated pulmonary arteries, possibly by production of ROS [104]. Thus, further studies with genetically altered subunits of NADPH oxidase are warranted to understand whether NADPH oxidases are indispensable for HPV.

In contrast to these studies showing increased hypoxic ROS release by NADPH oxidases, the groups of Wolin and Gupte expressed a hypothesis that is based on decreased ROS originating from NADPH oxidases as an underlying mechanism for HPV. It was initially proposed that bovine pulmonary arteries have unusually high glucose-6-phosphate dehydrogenase (G6PD) levels compared with systemic vessels. This high level of G6PD potentially results in higher NADPH concentrations as substrates for the NADPH oxidase, which thus could produce more $\mathrm{H}_{2} \mathrm{O}_{2}$ that causes cyclic guanosine monophosphate (cGMP)-dependent (via stimulation of soluble guanylate cyclase) and cGMP-independent vasodilation in normoxia [139, 140]. Hypoxia could inhibit Nox4-dependent $\mathrm{H}_{2} \mathrm{O}_{2}$ release and thus cause HPV [131]. In contrast, GUPTE et al. [141] showed in a recent study that increased G6PD activity during hypoxia resulted in increased cytosolic ROS concentration. Although the line of argumentation might seem contradictory, the importance for G6PD was proven by showing reduced HPV in G6PD-deficient mice, albeit specificity for the hypoxic response was not tested [139-141].

\section{Downstream targets of ROS}

In addition to the accumulating evidence of increased hypoxic ROS release in PASMCs originating either from mitochondria and/or NADPH oxidases, possible downstream targets of increased ROS have been identified. ROS can interfere with different pathways of HPV. Increased intracellular calcium inducing myosin light chain phosphorylation and contraction is achieved by calcium flow via plasmalemmal calcium channels, and possibly also by release of intracellularly stored calcium. As demonstrated very early, extracellular calcium inflow could be caused by opening of L-type calcium channels that could be activated by membrane depolarisation due to $\mathrm{K}_{\mathrm{V}}$ channel inhibition [77-79], while intracellular calcium release may occur mainly via ryanodine receptor (RyR) channels. Hypothetically, ROS could interact directly with L-type calcium channels or activate them via membrane depolarisation by inhibition of $\mathrm{K}_{\mathrm{V}}$ channels, which was recently shown in endothelium-denuded pulmonary arteries [125]. Redox regulation of L-type calcium channels and $\mathrm{K}_{\mathrm{V}}$ channels has been recently summarised $[99,142]$. However, the hypothesis is limited by the fact that inhibition of L-type calcium channels or genetic deletion of $\mathrm{K}_{V}$ channels only partially inhibited HPV [86, 143-145]. Moreover, ROS may trigger intracellular calcium release by interaction with sarcoplasmatic RyR receptors [146, 147], but the contribution of intracellular calcium release could not be shown in all studies [49].

As an extension of the primary hypothesis employing the L-type calcium channel $/ \mathrm{K}_{\mathrm{V}}$ channel axis, a mechanism involving the second messenger diacylglycerol (DAG) has recently been shown in HPV signalling.

It was discovered that transient receptor potential canonical channel type 6 (TRPC6) channels are essential for the hypoxic response in isolated lungs and PASMCs. TRPC6 is a nonselective cation channel (NSCC), belongs to the group of receptor-operated channels and has also been suggested to play a role in store-operated calcium entry [49]. The pivotal role of NSCCs had already been shown, as their inhibition completely abolished HPV [148]. Isolated lungs or PASMCs of mice deficient for TRPC6 channels lack acute HPV and hypoxia-induced increase in calcium, but not the response to sustained or chronic hypoxia [49]. Besides TRPC6 other TRP channels, such as transient receptor potential vanilloid channel type 4 (TRPV4), may also play a role in HPV, as deficiency in TRPV4 specifically attenuated HPV [149]. However, hitherto, only TRPC6 channels have been shown to be indispensable for HPV, at least in mice [49]. These channels gate calcium and sodium. In PASMCs they have been shown to contribute mainly to hypoxic plasma membrane depolarisation and opening of voltage-gated calcium channels, and to a lesser extent to a direct intracellular calcium increase [49]. Thus, their activation can provide an alternative $\mathrm{K}_{\mathrm{V}}$ channel- and L-type calcium channel-independent route of membrane depolarisation and intracellular calcium increase. Additionally, it can be speculated that sodium entry via TRPC6 channels could inhibit $\mathrm{K}_{\mathrm{V}}$ channels, as has been shown for other cell types [150].

TRPC6 channels can be activated by DAG, which is the product of phospholipases that can be regulated by ROS. This hypothesis is supported by investigations showing that DAG accumulated in hypoxia in PASMCs [49] and inhibition of DAG kinase or application of a DAG analogue could induce normoxic vasoconstriction in wild-type but not in TRPC6 knockout mice, and inhibit HPV specifically [151]. Inhibition of DAG synthesis by the phosphatidylinositol-specific phospholipase C (PI-PLC) inhibitor U73122 or the phosphatidylcholine-specific phospholipase C (PC-PLC) inhibitor D609 inhibited acute HPV (albeit not specifically) in isolated lungs [151], or reduced the acute phase and abolished the sustained phase of HPV in isolated rat intrapulmonary arteries [48], respectively. However, the role of the PI-PLC is not completely solved, as, in contrast to the previous study, U73122 did not inhibit hypoxia-induced 
calcium signals in human PASMCs, although a prominent role for TRPC6 was detected in these cells [145]. DAG kinase inhibition or phospholipase C (PLC) activation might be caused by superoxide [152, 153]. Moreover, D609 significantly suppressed pulmonary vasoconstriction induced with a generator of superoxide anions [48]. These observations support the idea that PLC enzymes may contribute to hypoxic DAG production and be activated by the increase in ROS generation in hypoxia. Interestingly, PC-PLC-dependent DAG production has also been shown to cause activation of sphingomyelinase [154], which was suggested to play an important role in HPV via increased ceramide production that could inhibit $\mathrm{K}_{\mathrm{V}}$ channels [122-124]. Very recently it was suggested that downstream signalling of nSMase also includes activation of TRPC6 by two concomitant ceramide-dependent mechanisms: 1) interaction of TRPC6 with the cystic fibrosis transmembrane conductance regulator (CFTR) and recruitment to caveolae, and 2) activation of sphingosine kinase 1 (SphK1) to activate the PLC-DAG-TRPC6 pathway. Intriguingly, CFTR deficiency specifically attenuated HPV [155]. Inhibition of nSMase and SphK1 abolished or attenuated HPV, respectively [155]. Although the specific role of nSMase in HPV and upstream mechanisms of nSMase activation, also with regard to potential ROS-dependent mechanisms, remain to be deciphered, this study elucidated a novel component of HPV that at least in part regulates HPV.

With regard to the role of DAG, there is evidence that DAG also activates PKCs, which in turn can activate NADPH oxidases and thus provide a positive feedback loop for ROS production. Mice deficient in PKC $\varepsilon$, whose activity is increased in endothelium-denuded pulmonary arteries [156], have specifically decreased HPV, which suggests that PKCE at least modifies the HPV response [157]. These results are consistent with studies employing PKC inhibitors, which decrease but do not abolish HPV [119, 158, 159].

Additionally, intracellular calcium release from RyR-sensitive calcium stores may contribute to HPV and activate store-operated channels (SOCs), the second group of NSCC. This process, called capacitative calcium entry, was suggested to be particularly important for contraction of pulmonary arteries [160]. Inhibitors of store-operated calcium entry (SOCE) decreased HPV [47]; however, the lack of identity of SOCs involved in HPV hampered further research. Recently, it has been shown that the acid-sensing ion channel 1 (ASIC1) contributes to SOCE in PASMCs [161] and deficiency of ASIC1 specifically blunted HPV due to decreased SOCE activation [162].

However, the importance of both extra- and intracellular calcium mechanisms is still a source of debate. While intracellular calcium release has been shown to be essential and sufficient for HPV [163-167], the same has been shown to be true for TRPC6-dependent mechanisms, which are currently known to induce only plasmalemmal calcium influx but not intracellular calcium release. However, the contribution of extra- and intracellular calcium release may rely on experimental conditions, specifically pre-tone. A recent study investigated hypoxia-induced contractions in endothelium-containing pulmonary arteries without pre-tone that may mask essential pathways of HPV by activating modulating or sensitising pathways [56]. Neither phase required calcium inflow via L-type calcium channels for contraction, but acute HPV relied on intracellular calcium release. While sustained HPV was dependent on SOCE, acute HPV was not inhibited by SOCE inhibitors. Thus, it was concluded that in HPV the L-type calcium channel/ $\mathrm{K}_{\mathrm{V}}$ channel axis is only important in pre-stimulated conditions. In line with that hypothesis, L-type calcium channel inhibitors inhibited acute HPV after pre-stimulation with prostaglandin F2 $\alpha$ [56]. Thus, both intra- and extracellular calcium release may contribute to HPV under different conditions to a different degree. In this regard it should be mentioned that TRPC6-deficient PASMCs were pre-stimulated with endothelin, which may enhance the importance of L-type calcium channels [49]. Moreover, the role of L-type calcium channels may differ in PASMCs derived from proximal or distal pulmonary arterial vessels.

Recently, an $\mathrm{HPV}$-initiating role for $\mathrm{H}_{2} \mathrm{O}_{2}$-dependent sensitisation of the extracellular calcium-sensing receptor was suggested [168], but could not be shown in unstimulated pulmonary arteries [56].

\section{ROS-independent triggers of HPV}

The discrepant findings with regard to ROS inhibitors and ROS detection in HPV have raised the question of whether other signalling molecules might be more important in HPV than ROS [169]. Moreover, the initial concept that mitochondrial complex I, II or III but not complex IV can act as oxygen sensor, which was based on the observations that cyanide application does not inhibit HPV $[60,73]$, was challenged by studies showing specific inhibition and mimicking of HPV by cyanide [62]. Thus, mitochondria may also initiate HPV by inhibition of mitochondrial respiration, e.g. via ATP signalling.

Although it is generally accepted that mitochondria are not inhibited during HPV to a degree that substantially influences ATP production, a small change in AMP/ATP ratio may act as a signalling mechanism. This hypothesis is based on the facts that 1) mitochondria are mildly inhibited during mild hypoxia determined by respiration measurements [64] and an increase of NADH/NAD ratio [170], but 2) no ATP depletion was observed during hypoxia in the whole lung $[65,66]$. However, a small change in 
AMP/ATP ratio could induce activation of AMP kinase, despite stable cellular ATP levels [171], which could cause calcium release from intracellular stores via cyclic adenosine diphosphoribose [172]. Although activation of AMP kinase induced a biphasic vasoconstriction in pulmonary arteries [171], application of the AMP kinase inhibitor compound C inhibited sustained HPV but not acute HPV in pulmonary arteries [173]. Moreover, without pre-stimulation, compound C inhibited HPV nonspecifically [56].

A small decrease in ATP may also open mitochondrial ATP-dependent potassium ( mitoK $_{\mathrm{ATP}}$ ) channels, which can increase ROS production under specific conditions [174]. In this regard, inhibitors of mitoK $\mathrm{ATP}_{\mathrm{ATP}}$ completely inhibited HPV [175], although their specificity for mito $\mathrm{K}_{\mathrm{ATP}}$ channels is under debate [176].

Recently, a new potential mediator has come to the fore. It was suggested that hypoxia increases $\mathrm{H}_{2} \mathrm{~S}$ concentration in different mammalian tissues [177] and suppresses mitochondrial $\mathrm{H}_{2} \mathrm{~S}$ consumption in a $\mathrm{PO}_{2}$-dependent manner, thereby leading to increased mitochondrial ROS production [178, 179]. Inhibition of $\mathrm{H}_{2} \mathrm{~S}$ production inhibited hypoxic responses in trout gills, but the specificity of inhibition for HPV was not tested [179]. However, serious doubts have been expressed as to the relevance of this pathway, as inhibitors of the $\mathrm{H}_{2} \mathrm{~S}$-synthesising pathway did not inhibit HPV in isolated pulmonary arteries [180].

\section{Outlook}

Oxygen sensing and signal transduction in acute HPV is intrinsic to PASMCs, but may depend in vivo on pre-conditioning from other cell types, especially the endothelium. Contraction of PASMCs in response to hypoxia is the result of a complex interaction between triggering and modulating factors that culminate in intracellular calcium increase and myosin light chain phosphorylation. A decrease in mitochondrial ROS production, as well as an increased ROS release by mitochondria, have both been suggested as potential oxygen-sensing mechanisms. Early proposals for downstream mechanisms included the alteration of the cellular redox state, activation of intracellular calcium release and/or inhibition of $K_{V}$ channels, thereby opening L-type calcium channels. More recently, this fundamental hypothesis of signal transduction has been questioned, although there is no doubt that $\mathrm{K}_{\mathrm{V}}$ channels close during hypoxia. As a novel key player in HPV signalling, the second messenger DAG and its interaction with TRPC6 channels has evolved. DAG can be produced by ROS-dependent activation of phospholipases and not only interacts with TRPC6 channels but also activates PKC subtypes, as well as ceramide production, which might in turn increase ROS production by NADPH oxidase or inhibit $\mathrm{K}_{\mathrm{V}}$ channels, respectively. At least in mice, acute HPV is transmitted by TRPC6 channel activation, possibly via $\mathrm{K}_{\mathrm{V}}$ channel-dependent membrane depolarisation and subsequent opening of voltage-dependent cation channels. The importance of intracellular calcium release is under debate, but may depend on experimental settings and site of investigation. Moreover, the mechanism of mitochondrial ROS production remains to be further elucidated in detail.

\section{References}

1 Weissmann N, Akkayagil E, Quanz K, et al. Basic features of hypoxic pulmonary vasoconstriction in mice. Respir Physiol Neurobiol 2004; 139: 191-202.

2 Weissmann N, Grimminger F, Walmrath D, et al. Hypoxic vasoconstriction in buffer-perfused rabbit lungs. Respir Physiol 1995; 100: 159-169.

3 Lindgren L, Marshall C, Marshall BE. Hypoxic pulmonary vasoconstriction in isolated rat lungs perfused with perfluorocarbon emulsion. Acta Physiol Scand 1985; 123: 335-338.

4 Peake MD, Harabin AL, Brennan NJ, et al. Steady-state vascular responses to graded hypoxia in isolated lungs of five species. J Appl Physiol Respir Environ Exerc Physiol 1981; 51: 1214-1219.

5 Faraci FM, Kilgore DL Jr, Fedde MR. Attenuated pulmonary pressor response to hypoxia in bar-headed geese. Am J Physiol 1984; 247: R402-R403.

6 Malvin GM, Walker BR. Sites and ionic mechanisms of hypoxic vasoconstriction in frog skin. Am J Physiol Regul Integr Comp Physiol 2001; 280: R1308-R1314.

7 Skovgaard N, Abe AS, Andrade DV, et al. Hypoxic pulmonary vasoconstriction in reptiles: a comparative study of four species with different lung structures and pulmonary blood pressures. Am J Physiol Regul Integr Comp Physiol 2005; 289: R1280-R1288.

8 Olson KR, Russell MJ, Forster ME. Hypoxic vasoconstriction of cyclostome systemic vessels: the antecedent of hypoxic pulmonary vasoconstriction? Am J Physiol Regul Integr Comp Physiol 2001; 280: R198-R206.

9 Smith MP, Russell MJ, Wincko JT, et al. Effects of hypoxia on isolated vessels and perfused gills of rainbow trout. Comp Biochem Physiol A Mol Integr Physiol 2001; 130: 171-181.

10 Lumb AB, Slinger P. Hypoxic pulmonary vasoconstriction: physiology and anesthetic implications. Anesthesiology 2015; 122: 932-946.

11 Marshall BE. Hypoxic pulmonary vasoconstriction. Acta Anaesthesiol Scand Suppl 1990; 94: 37-41.

12 Naeije R, Brimioulle S. Physiology in medicine: importance of hypoxic pulmonary vasoconstriction in maintaining arterial oxygenation during acute respiratory failure. Crit Care 2001; 5: 67-71.

13 Carter EP, Hartsfield CL, Miyazono $M$, et al. Regulation of heme oxygenase-1 by nitric oxide during hepatopulmonary syndrome. Am J Physiol Lung Cell Mol Physiol 2002; 283: L346-L353.

14 Sylvester JT, Shimoda LA, Aaronson PI, et al. Hypoxic pulmonary vasoconstriction. Physiol Rev 2012; 92 : $367-520$.

15 Weir EK. Does normoxic pulmonary vasodilatation rather than hypoxic vasoconstriction account for the pulmonary pressor response to hypoxia? Lancet 1978; 1: 476-477. 
Bradford JR, Dean HP. The pulmonary circulation. J Physiol 1894; 16: 34-158.

Plumier L. La circulation pulmonaire chez le chien [Pulmonary circulation in the dog]. Arch Intern Physiol 1904; 1: $176-213$.

Von Euler US, Liljestrand G. Observations on the pulmonary arterial blood pressure in the cat. Acta Physiol Scand 1946; 12: 301-320.

Motley HL, Cournand A, Werko L, et al. The influence of short periods of induced acute anoxia upon pulmonary artery pressures in man. Am J Physiol 1947; 150: 315-320.

Ariyaratnam P, Loubani M, Morice AH. Hypoxic pulmonary vasoconstriction in humans. Biomed Res Int 2013; 2013: 623684

Hillier SC, Graham JA, Hanger CC, et al. Hypoxic vasoconstriction in pulmonary arterioles and venules. J Appl Physiol 1997; 82: 1084-1090.

Staub NC. Site of hypoxic pulmonary vasoconstriction. Chest 1985; 88: Suppl. 4, 240S-245S.

19: 426-440.

Dawson CA, Grimm DJ, Linehan JH. Influence of hypoxia on the longitudinal distribution of pulmonary vascular resistance. J Appl Physiol Respir Environ Exerc Physiol 1978; 44: 493-498.

Marshall BE, Marshall C, Benumof J, et al. Hypoxic pulmonary vasoconstriction in dogs: effects of lung segment size and oxygen tension. J Appl Physiol Respir Environ Exerc Physiol 1981; 51: 1543-1551. 1983; 52: 691-696.

Leach RM, Robertson TP, Twort $\mathrm{CH}$, et al. Hypoxic vasoconstriction in rat pulmonary and mesenteric arteries. Am J Physiol 1994; 266: L223-L231.

Murray TR, Chen L, Marshall BE, et al. Hypoxic contraction of cultured pulmonary vascular smooth muscle cells. Am J Respir Cell Mol Biol 1990; 3: 457-465.

Madden JA, Vadula MS, Kurup VP. Effects of hypoxia and other vasoactive agents on pulmonary and cerebral artery smooth muscle cells. Am J Physiol 1992; 263: L384-L393.

Vadula MS, Kleinman JG, Madden JA. Effect of hypoxia and norepinephrine on cytoplasmic free $\mathrm{Ca}^{2+}$ in pulmonary and cerebral arterial myocytes. Am J Physiol 1993; 265: L591-L597.

Salvaterra CG, Goldman WF. Acute hypoxia increases cytosolic calcium in cultured pulmonary arterial myocytes. Am J Physiol 1993; 264: L323-L328.

Fishman AP. Hypoxia on the pulmonary circulation. How and where it acts. Circ Res 1976; 38: 221-231.

Cutaia M, Rounds S. Hypoxic pulmonary vasoconstriction. Physiologic significance, mechanism, and clinical relevance. Chest 1990; 97: 706-718.

Davis MJ, Joyner WL, Gilmore JP. Microvascular pressure distribution and responses of pulmonary allografts and cheek pouch arterioles in the hamster to oxygen. Circ Res 1981; 49: 125-132.

van Heerden PV, Cameron PD, Karanovic A, et al. Orthodeoxia - an uncommon presentation following bilateral thoracic sympathectomy. Anaesth Intensive Care 2003; 31: 581-583.

Brimioulle S, Vachiéry JL, Brichant JF, et al. Sympathetic modulation of hypoxic pulmonary vasoconstriction in intact dogs. Cardiovasc Res 1997; 34: 384-392.

Frostell C, Fratacci MD, Wain JC, et al. Inhaled nitric oxide. A selective pulmonary vasodilator reversing hypoxic pulmonary vasoconstriction. Circulation 1991; 83: 2038-2047.

Weissmann N, Winterhalder S, Nollen M, et al. NO and reactive oxygen species are involved in biphasic hypoxic vasoconstriction of isolated rabbit lungs. Am J Physiol Lung Cell Mol Physiol 2001; 280: L638-L645.

Bernal PJ, Leelavanichkul K, Bauer E, et al. Nitric-oxide-mediated zinc release contributes to hypoxic regulation of pulmonary vascular tone. Circ Res 2008; 102: 1575-1583.

Lahm T, Crisostomo PR, Markel TA, et al. Exogenous estrogen rapidly attenuates pulmonary artery vasoreactivity and acute hypoxic pulmonary vasoconstriction. Shock 2008; 30: 660-667.

Farrukh IS, Peng W, Orlinska U, et al. Effect of dehydroepiandrosterone on hypoxic pulmonary vasoconstriction: a $\mathrm{Ca}^{2+}$-activated $\mathrm{K}^{+}$-channel opener. Am J Physiol 1998; 274: L186-L195.

Abid S, Houssaïni A, Mouraret N, et al. P21-dependent protective effects of a carbon monoxide-releasing molecule-3 in pulmonary hypertension. Arterioscler Thromb Vasc Biol 2014; 34: 304-312.

Ketabchi F, Egemnazarov B, Schermuly RT, et al. Effects of hypercapnia with and without acidosis on hypoxic pulmonary vasoconstriction. Am J Physiol Lung Cell Mol Physiol 2009; 297: L977-L983.

Deem S, Berg JT, Kerr ME, et al. Effects of the RBC membrane and increased perfusate viscosity on hypoxic pulmonary vasoconstriction. J Appl Physiol 2000; 88: 1520-1528.

Shimoda LA, Laurie SS. HIF and pulmonary vascular responses to hypoxia. J Appl Physiol 2014; 116: 867-874. vasoconstriction. Proc Natl Acad Sci USA 2013; 110: 18710-18715. prostaglandin E2 during hypoxia. PLoS One 2013; 8: e73839.

Strielkov IV, Kizub IV, Khromov AS, et al. Evidence for the role of phosphatidylcholine-specific phospholipase C in sustained hypoxic pulmonary vasoconstriction. Vascul Pharmacol 2013; 58: 292-298.

Weissmann N, Dietrich A, Fuchs B, et al. Classical transient receptor potential channel 6 (TRPC6) is essential for hypoxic pulmonary vasoconstriction and alveolar gas exchange. Proc Natl Acad Sci USA 2006; 103: 19093-19098. Leach RM, Hill HM, Snetkov VA, et al. Divergent roles of glycolysis and the mitochondrial electron transport chain in hypoxic pulmonary vasoconstriction of the rat: identity of the hypoxic sensor. J Physiol 2001; 536: 211-224.

Demiryurek AT, Wadsworth RM, Kane KA, et al. The role of endothelium in hypoxic constriction of human pulmonary artery rings. Am Rev Respir Dis 1993; 147: 283-290.

Demiryurek AT, Wadsworth RM, Kane KA. Effects of hypoxia on isolated intrapulmonary arteries from the sheep. Pulm Pharmacol 1991; 4: 158-164.

Liu Q, Sham JS, Shimoda LA, et al. Hypoxic constriction of porcine distal pulmonary arteries: endothelium and endothelin dependence. Am J Physiol Lung Cell Mol Physiol 2001; 280: L856-L865.

Aaronson PI, Robertson TP, Ward JP. Endothelium-derived mediators and hypoxic pulmonary vasoconstriction. Respir Physiol Neurobiol 2002; 132: 107-120. 
Robertson TP, Hague D, Aaronson PI, et al. Voltage-independent calcium entry in hypoxic pulmonary vasoconstriction of intrapulmonary arteries of the rat. J Physiol 2000; 525: 669-680.

Connolly MJ, Prieto-Lloret J, Becker S, et al. Hypoxic pulmonary vasoconstriction in the absence of pretone: essential role for intracellular $\mathrm{Ca}^{2+}$ release. J Physiol 2013; 591: 4473-4498.

Wang L, Yin J, Nickles HT, et al. Hypoxic pulmonary vasoconstriction requires connexin 40-mediated endothelial signal conduction. J Clin Invest 2012; 122: 4218-4230.

Weir EK, Olschewski A. Role of ion channels in acute and chronic responses of the pulmonary vasculature to hypoxia. Cardiovasc Res 2006; 71: 630-641.

Robertson TP. Point: Release of an endothelium-derived vasoconstrictor and RhoA/Rho kinase-mediated calcium sensitization of smooth muscle cell contraction are/are not the main effectors for full and sustained hypoxic pulmonary vasoconstriction. J Appl Physiol 2007; 102: 2071-2072.

Waypa GB, Chandel NS, Schumacker PT. Model for hypoxic pulmonary vasoconstriction involving mitochondrial oxygen sensing. Circ Res 2001; 88: 1259-1266.

Rounds S, McMurtry IF. Inhibitors of oxidative ATP production cause transient vasoconstriction and block subsequent pressor responses in rat lungs. Circ Res 1981; 48: 393-400.

Weissmann N, Ebert N, Ahrens M, et al. Effects of mitochondrial inhibitors and uncouplers on hypoxic vasoconstriction in rabbit lungs. Am J Respir Cell Mol Biol 2003; 29: 721-732.

Michelakis ED, Thébaud $\mathrm{B}$, Weir EK, et al. Hypoxic pulmonary vasoconstriction: redox regulation of $\mathrm{O}_{2}$-sensitive $\mathrm{K}^{+}$channels by a mitochondrial $\mathrm{O}_{2}$-sensor in resistance artery smooth muscle cells. J Mol Cell Cardiol 2004; 37: 1119-1136.

Sommer N, Pak O, Schörner S, et al. Mitochondrial cytochrome redox states and respiration in acute pulmonary oxygen sensing. Eur Respir J 2010; 36: 1056-1066.

Buescher PC, Pearse DB, Pillai RP, et al. Energy state and vasomotor tone in hypoxic pig lungs. J Appl Physiol 1991; 70: 1874-1881.

Fisher AB, Dodia C. Lung as a model for evaluation of critical intracellular $P_{\mathrm{O}_{2}}$ and PCO. Am J Physiol 1981; 241: E47-E50.

Leach RM, Hill HS, Snetkov VA, et al. Hypoxia, energy state and pulmonary vasomotor tone. Respir Physiol Neurobiol 2002; 132: 55-67.

Sylvester JT. Hypoxic pulmonary vasoconstriction: a radical view. Circ Res 2001; 88: 1228-1230.

Sham JS. Hypoxic pulmonary vasoconstriction: ups and downs of reactive oxygen species. Circ Res 2002; 91: 649-651.

Waypa GB, Schumacker PT. Hypoxic pulmonary vasoconstriction: redox events in oxygen sensing. J Appl Physiol 2005; 98: 404-414.

Moudgil R, Michelakis ED, Archer SL. Hypoxic pulmonary vasoconstriction. J Appl Physiol 2005; 98: 390-403.

Ward JP. Point: Hypoxic pulmonary vasoconstriction is mediated by increased production of reactive oxygen species. J Appl Physiol 2006; 101: 993-995.

Archer SL, Huang J, Henry T, et al. A redox-based $\mathrm{O}_{2}$ sensor in rat pulmonary vasculature. Circ Res 1993; 73 : $1100-1112$.

Michelakis ED, Hampl V, Nsair A, et al. Diversity in mitochondrial function explains differences in vascular oxygen sensing. Circ Res 2002; 90: 1307-1315.

Michelakis ED, Archer SL, Weir EK. Acute hypoxic pulmonary vasoconstriction: a model of oxygen sensing. Physiol Res 1995; 44: 361-367.

Weir EK, Archer SL. The mechanism of acute hypoxic pulmonary vasoconstriction: the tale of two channels. FASEB J 1995; 9: 183-189.

Yuan XJ, Goldman WF, Tod ML, et al. Hypoxia reduces potassium currents in cultured rat pulmonary but not mesenteric arterial myocytes. Am J Physiol 1993; 264: L116-L123.

Post JM, Hume JR, Archer SL, et al. Direct role for potassium channel inhibition in hypoxic pulmonary vasoconstriction. Am J Physiol 1992; 262: C882-C890.

Hasunuma K, Rodman DM, McMurtry IF. Effects of $\mathrm{K}^{+}$channel blockers on vascular tone in the perfused rat lung. Am Rev Respir Dis 1991; 144: 884-887.

Patel AJ, Lazdunski M, Honoré E. Kv2.1/Kv9.3, a novel ATP-dependent delayed-rectifier $\mathrm{K}^{+}$channel in oxygen-sensitive pulmonary artery myocytes. EMBO J 1997; 16: 6615-6625.

Hulme JT, Coppock EA, Felipe A, et al. Oxygen sensitivity of cloned voltage-gated $\mathrm{K}^{+}$channels expressed in the pulmonary vasculature. Circ Res 1999; 85: 489-497.

Archer SL, Souil E, Dinh-Xuan AT, et al. Molecular identification of the role of voltage-gated $\mathrm{K}^{+}$channels, Kv1.5 and $\mathrm{Kv} 2.1$, in hypoxic pulmonary vasoconstriction and control of resting membrane potential in rat pulmonary artery myocytes. J Clin Invest 1998; 101: 2319-2330.

Reeve HL, Weir EK, Nelson DP, et al. Opposing effects of oxidants and antioxidants on $\mathrm{K}^{+}$channel activity and tone in rat vascular tissue. Exp Physiol 1995; 80: 825-834.

Park MK, Bae YM, Lee SH, et al. Modulation of voltage-dependent $\mathrm{K}^{+}$channel by redox potential in pulmonary and ear arterial smooth muscle cells of the rabbit. Pflugers Arch 1997; 434: 764-771.

Firth AL, Gordienko DV, Yuill KH, et al. Cellular localization of mitochondria contributes to Kv channel-mediated regulation of cellular excitability in pulmonary but not mesenteric circulation. Am J Physiol Lung Cell Mol Physiol 2009; 296: L347-L360.

Archer SL, London B, Hampl V, et al. Impairment of hypoxic pulmonary vasoconstriction in mice lacking the voltage-gated potassium channel Kv1.5. FASEB J 2001; 15: 1801-1803.

Sommer N, Dietrich A, Schermuly RT, et al. Regulation of hypoxic pulmonary vasoconstriction: basic mechanisms. Eur Respir J 2008; 32: 1639-1651.

Archer S, Michelakis E. The mechanism(s) of hypoxic pulmonary vasoconstriction: potassium channels, redox $\mathrm{O}_{2}$ sensors, and controversies. News Physiol Sci 2002; 17: 131-137.

Dikalov S, Griendling KK, Harrison DG. Measurement of reactive oxygen species in cardiovascular studies. Hypertension 2007; 49: 717-727.

Waypa GB, Marks JD, Guzy R, et al. Hypoxia triggers subcellular compartmental redox signaling in vascular smooth muscle cells. Circ Res 2010; 106: 526-535. 
Weissmann N, Zeller S, Schäfer RU, et al. Impact of mitochondria and NADPH oxidases on acute and sustained hypoxic pulmonary vasoconstriction. Am J Respir Cell Mol Biol 2006; 34: 505-513.

92 Desireddi JR, Farrow KN, Marks JD, et al. Hypoxia increases ROS signaling and cytosolic Ca ${ }^{2+}$ in pulmonary artery smooth muscle cells of mouse lungs slices. Antioxid Redox Signal 2010; 12: 595-602.

93 Sheehan DW, Giese EC, Gugino SF, et al. Characterization and mechanisms of $\mathrm{H}_{2} \mathrm{O}_{2}$-induced contractions of pulmonary arteries. Am J Physiol 1993; 264: H1542-H1547.

94 Jones RD, Thompson JS, Morice AH. The effect of hydrogen peroxide on hypoxia, prostaglandin F2 alpha and potassium chloride induced contractions in isolated rat pulmonary arteries. Pulm Pharmacol Ther 1997; 10: 37-42. Olschewski A, Hong Z, Peterson DA, et al. Opposite effects of redox status on membrane potential, cytosolic calcium, and tone in pulmonary arteries and ductus arteriosus. Am J Physiol Lung Cell Mol Physiol 2004; 286: L15-L22.

96 Pourmahram GE, Snetkov VA, Shaifta Y, et al. Constriction of pulmonary artery by peroxide: Role of Ca ${ }^{2+}$ release and PKC. Free Radic Biol Med 2008; 45: 1468-1476.

97 Weir EK, Eaton JW, Chesler E. Redox status and pulmonary vascular reactivity. Chest 1985; 88: Suppl. 4, 249S-252S.

98 Hodyc D, Snorek M, Brtnicky T, et al. Superoxide dismutase mimetic tempol inhibits hypoxic pulmonary vasoconstriction in rats independently of nitric oxide production. Exp Physiol 2007; 92: 945-951.

99 Veit F, Pak O, Brandes RP, et al. Hypoxia-dependent reactive oxygen species signaling in the pulmonary circulation: focus on ion channels. Antioxid Redox Signal 2015; 22: 537-552.

100 Weissmann N, Grimminger F, Voswinckel R, et al. Nitro blue tetrazolium inhibits but does not mimic hypoxic vasoconstriction in isolated rabbit lungs. Am J Physiol 1998; 274: L721-L727.

101 Paky A, Michael JR, Burke-Wolin TM, et al. Endogenous production of superoxide by rabbit lungs: effects of hypoxia or metabolic inhibitors. J Appl Physiol 1993; 74: 2868-2874.

102 Waypa GB, Guzy R, Mungai PT, et al. Increases in mitochondrial reactive oxygen species trigger hypoxia-induced calcium responses in pulmonary artery smooth muscle cells. Circ Res 2006; 99: 970-978.

103 Wang QS, Zheng YM, Dong L, et al. Role of mitochondrial reactive oxygen species in hypoxia-dependent increase in intracellular calcium in pulmonary artery myocytes. Free Radic Biol Med 2007; 42: 642-653.

104 Zaloudikova M, Herget J, Vizek M. The contractile response of isolated small pulmonary arteries induced by activated macrophages. Physiol Res 2014; 63: 267-270.

105 Turrens JF, Alexandre A, Lehninger AL. Ubisemiquinone is the electron donor for superoxide formation by complex III of heart mitochondria. Arch Biochem Biophys 1985; 237: 408-414.

106 Paddenberg R, Ishaq B, Goldenberg A, et al. Essential role of complex II of the respiratory chain in hypoxia-induced ROS generation in the pulmonary vasculature. Am J Physiol Lung Cell Mol Physiol 2003; 284: L710-L719.

107 Brookes PS, Yoon Y, Robotham JL, et al. Calcium, ATP, and ROS: a mitochondrial love-hate triangle. Am J Physiol Cell Physiol 2004; 287: C817-C833.

108 Andrukhiv A, Costa AD, West IC, et al. Opening mitoK $\mathrm{ATP}_{\mathrm{T}}$ increases superoxide generation from complex I of the electron transport chain. Am J Physiol Heart Circ Physiol 2006; 291: H2067-H2074.

109 Bleier L, Dröse S. Superoxide generation by complex III: from mechanistic rationales to functional consequences Biochim Biophys Acta 2013; 1827: 1320-1331.

110 Korde AS, Yadav VR, Zheng YM, et al. Primary role of mitochondrial Rieske iron-sulfur protein in hypoxic ROS production in pulmonary artery myocytes. Free Radic Biol Med 2011; 50: 945-952.

111 Waypa GB, Marks JD, Guzy RD, et al. Superoxide generated at mitochondrial complex III triggers acute responses to hypoxia in the pulmonary circulation. Am J Respir Crit Care Med 2013; 187: 424-432.

112 Schumacker PT. Lung cell hypoxia: role of mitochondrial reactive oxygen species signaling in triggering responses. Proc Am Thorac Soc 2011; 8: 477-484.

113 Chen Q, Vazquez EJ, Moghaddas S, et al. Production of reactive oxygen species by mitochondria: central role of complex III. J Biol Chem 2003; 278: 36027-36031.

114 Paddenberg R, Tiefenbach M, Faulhammer P, et al. Mitochondrial complex II is essential for hypoxia-induced pulmonary vasoconstriction of intra- but not of pre-acinar arteries. Cardiovasc Res 2012; 93: 702-710.

115 Marshall C, Mamary AJ, Verhoeven AJ, et al. Pulmonary artery NADPH-oxidase is activated in hypoxic pulmonary vasoconstriction. Am J Respir Cell Mol Biol 1996; 15: 633-644.

116 Mittal M, Gu XQ, Pak O, et al. Hypoxia induces Kv channel current inhibition by increased NADPH oxidase-derived reactive oxygen species. Free Radic Biol Med 2012; 52: 1033-1042.

117 Gabig TG, Bearman SI, Babior BM. Effects of oxygen tension and $\mathrm{pH}$ on the respiratory burst of human neutrophils. Blood 1979; 53: 1133-1139.

118 Weissmann N, Kuzkaya N, Fuchs B, et al. Detection of reactive oxygen species in isolated, perfused lungs by electron spin resonance spectroscopy. Respir Res 2005; 6: 86

119 Weissmann N, Voswinckel R, Hardebusch T, et al. Evidence for a role of protein kinase C in hypoxic pulmonary vasoconstriction. Am J Physiol 1999; 276: L90-L95.

120 Ward JP, Knock GA, Snetkov VA, et al. Protein kinases in vascular smooth muscle tone - role in the pulmonary vasculature and hypoxic pulmonary vasoconstriction. Pharmacol Ther 2004; 104: 207-231.

121 Rathore R, Zheng YM, Niu CF, et al. Hypoxia activates NADPH oxidase to increase $[\mathrm{ROS}]_{\mathrm{i}}$ and $\left[\mathrm{Ca}{ }^{2+}\right]_{\mathrm{i}}$ through mitochondrial ROS-PKCe signaling axis in pulmonary artery smooth muscle cells. Free Radic Biol Med 2008; 45: 1223-1231.

122 Moral-Sanz J, Gonzalez T, Menendez C, et al. Ceramide inhibits $\mathrm{K}_{\mathrm{V}}$ currents and contributes to TP-receptor-induced vasoconstriction in rat and human pulmonary arteries. Am J Physiol Cell Physiol 2011; 301: C186-C194.

123 Cogolludo A, Moreno L, Frazziano G, et al. Activation of neutral sphingomyelinase is involved in acute hypoxic pulmonary vasoconstriction. Cardiovasc Res 2009; 82: 296-302.

124 Moreno L, Moral-Sanz J, Morales-Cano D, et al. Ceramide mediates acute oxygen sensing in vascular tissues. Antioxid Redox Signal 2014; 20: 1-14.

125 Frazziano G, Moreno L, Moral-Sanz J, et al. Neutral sphingomyelinase, NADPH oxidase and reactive oxygen species. Role in acute hypoxic pulmonary vasoconstriction. J Cell Physiol 2011; 226: 2633-2640.

126 Archer SL, Reeve HL, Michelakis E, et al. $\mathrm{O}_{2}$ sensing is preserved in mice lacking the gp91 phox subunit of NADPH oxidase. Proc Natl Acad Sci USA 1999; 96: 7944-7949. 
Sumimoto H, Miyano K, Takeya R. Molecular composition and regulation of the Nox family NAD(P)H oxidases. Biochem Biophys Res Commun 2005; 338: 677-686.

Mittal M, Roth M, König P, et al. Hypoxia-dependent regulation of nonphagocytic NADPH oxidase subunit NOX4 in the pulmonary vasculature. Circ Res 2007; 101: 258-267.

Wedgwood S, Lakshminrusimha S, Czech L, et al. Increased $\mathrm{p} 22^{\mathrm{phox}} / \mathrm{Nox} 4$ expression is involved in remodeling through hydrogen peroxide signaling in experimental persistent pulmonary hypertension of the newborn. Antioxid Redox Signal 2013; 18: 1765-1776.

Pendyala S, Moitra J, Kalari S, et al. Nrf2 regulates hyperoxia-induced Nox4 expression in human lung endothelium: identification of functional antioxidant response elements on the Nox4 promoter. Free Radic Biol Med 2011; 50: 1749-1759.

Ahmad M, Kelly MR, Zhao X, et al. Roles for Nox4 in the contractile response of bovine pulmonary arteries to hypoxia. Am J Physiol Heart Circ Physiol 2010; 298: H1879-H1888.

Lee YM, Kim BJ, Chun YS, et al. Nox4 as an oxygen sensor to regulate TASK-1 activity. Cell Signal 2006; 18: 499-507.

Olschewski A, Li Y, Tang B, et al. Impact of TASK-1 in human pulmonary artery smooth muscle cells. Circ Res 2006; 98: 1072-1080.

Nagaraj C, Tang B, Balint Z, et al. Src tyrosine kinase is crucial for potassium channel function in human pulmonary arteries. Eur Respir J 2013; 41: 85-95.

Thomas HM 3rd, Carson RC, Fried ED, et al. Inhibition of hypoxic pulmonary vasoconstriction by diphenyleneiodonium. Biochem Pharmacol 1991; 42: R9-R12.

Grimminger F, Weissmann N, Spriestersbach R, et al. Effects of NADPH oxidase inhibitors on hypoxic vasoconstriction in buffer-perfused rabbit lungs. Am J Physiol 1995; 268: L747-L752.

Jones RD, Thompson JS, Morice AH. The NADPH oxidase inhibitors iodonium diphenyl and cadmium sulphate inhibit hypoxic pulmonary vasoconstriction in isolated rat pulmonary arteries. Physiol Res 2000; 49: 587-596.

Weissmann N, Tadic A, Hänze J, et al. Hypoxic vasoconstriction in intact lungs: a role for NADPH oxidase-derived $\mathrm{H}_{2} \mathrm{O}_{2}$ ? Am J Physiol Lung Cell Mol Physiol 2000; 279: L683-L690.

Mingone CJ, Gupte SA, Iesaki T, et al. Hypoxia enhances a cGMP-independent nitric oxide relaxing mechanism in pulmonary arteries. Am J Physiol Lung Cell Mol Physiol 2003; 285: L296-L304.

Wolin MS, Ahmad M, Gupte SA. Oxidant and redox signaling in vascular oxygen sensing mechanisms: basic concepts, current controversies, and potential importance of cytosolic NADPH. Am J Physiol Lung Cell Mol Physiol 2005; 289: L159-L173.

Gupte RS, Rawat DK, Chettimada S, et al. Activation of glucose-6-phosphate dehydrogenase promotes acute hypoxic pulmonary artery contraction. J Biol Chem 2010; 285: 19561-19571.

Olschewski A, Weir EK. Redox regulation of ion channels in the pulmonary circulation. Antioxid Redox Signal 2015; 22: 465-485.

Ohe M, Ogata M, Shirato K, et al. Effects of verapamil and BAY K 8644 on the hypoxic contraction of the isolated human pulmonary artery. Tohoku J Exp Med 1989; 157: 81-82.

Tucker A, McMurtry IF, Grover RF, et al. Attenuation of hypoxic pulmonary vasoconstriction by verapamil in intact dogs. Proc Soc Exp Biol Med 1976; 151: 611-614.

Tang C, To WK, Meng F, et al. A role for receptor-operated $\mathrm{Ca}^{2+}$ entry in human pulmonary artery smooth muscle cells in response to hypoxia. Physiol Res 2010; 59: 909-918.

Lin MJ, Yang XR, Cao YN, et al. Hydrogen peroxide-induced $\mathrm{Ca}^{2+}$ mobilization in pulmonary arterial smooth muscle cells. Am J Physiol Lung Cell Mol Physiol 2007; 292: L1598-L1608.

Liao B, Zheng YM, Yadav VR, et al. Hypoxia induces intracellular $\mathrm{Ca}^{2+}$ release by causing reactive oxygen species-mediated dissociation of FK506-binding protein 12.6 from ryanodine receptor 2 in pulmonary artery myocytes. Antioxid Redox Signal 2011; 14: 37-47.

Weigand L, Foxson J, Wang J, et al. Inhibition of hypoxic pulmonary vasoconstriction by antagonists of store-operated $\mathrm{Ca}^{2+}$ and nonselective cation channels. Am J Physiol Lung Cell Mol Physiol 2005; 289 : L5-L13.

Goldenberg NM, Wang L, Ranke $\mathrm{H}$, et al. TRPV4 is required for hypoxic pulmonary vasoconstriction. Anesthesiology 2015; 122: 1338-1348.

French RJ, Wells JB. Sodium ions as blocking agents and charge carriers in the potassium channel of the squid giant axon. J Gen Physiol 1977; 70: 707-724.

Fuchs B, Rupp M, Ghofrani HA, et al. Diacylglycerol regulates acute hypoxic pulmonary vasoconstriction via TRPC6. Respir Res 2011; 12: 20.

Weissmann N, Sydykov A, Kalwa H, et al. Activation of TRPC6 channels is essential for lung ischaemia-reperfusion induced oedema in mice. Nat Commun 2012; 3: 649.

Liu H, Zhang H, Forman HJ. Silica induces macrophage cytokines through phosphatidylcholine-specific phospholipase C with hydrogen peroxide. Am J Respir Cell Mol Biol 2007; 36: 594-599.

Monick MM, Carter AB, Gudmundsson G, et al. A phosphatidylcholine-specific phospholipase C regulates activation of p42/44 mitogen-activated protein kinases in lipopolysaccharide-stimulated human alveolar macrophages. J Immunol 1999; 162: 3005-3012.

Tabeling C, Yu H, Wang L, et al. CFTR and sphingolipids mediate hypoxic pulmonary vasoconstriction. Proc Natl Acad Sci USA 2015; 112: E1614-E1623.

Rathore R, Zheng YM, Li XQ, et al. Mitochondrial ROS-PKCe signaling axis is uniquely involved in hypoxic increase in $\left[\mathrm{Ca}^{2+}\right]_{\mathrm{i}}$ in pulmonary artery smooth muscle cells. Biochem Biophys Res Commun 2006; 351: 784-790. Littler CM, Morris KG Jr, Fagan KA, et al. Protein kinase C- $\varepsilon$-null mice have decreased hypoxic pulmonary vasoconstriction. Am J Physiol Heart Circ Physiol 2003; 284: H1321-H1331.

Jin N, Packer CS, Rhoades RA. Pulmonary arterial hypoxic contraction: signal transduction. Am J Physiol 1992; 263: L73-L78.

9 Tsai BM, Wang M, Pitcher JM, et al. Hypoxic pulmonary vasoconstriction and pulmonary artery tissue cytokine expression are mediated by protein kinase C. Am J Physiol Lung Cell Mol Physiol 2004; 287: L1215-L1219.

Snetkov VA, Aaronson PI, Ward JP, et al. Capacitative calcium entry as a pulmonary specific vasoconstrictor mechanism in small muscular arteries of the rat. Br J Pharmacol 2003; 140: 97-106.

Jernigan NL, Paffett ML, Walker BR, et al. ASIC1 contributes to pulmonary vascular smooth muscle store-operated $\mathrm{Ca}^{2+}$ entry. Am J Physiol Lung Cell Mol Physiol 2009; 297: L271-L285. 
Nitta CH, Osmond DA, Herbert LM, et al. Role of ASIC1 in the development of chronic hypoxia-induced pulmonary hypertension. Am J Physiol Heart Circ Physiol 2014; 306: H41-H52.

163 Gelband $\mathrm{CH}$, Gelband $\mathrm{H}$. $\mathrm{Ca}^{2+}$ release from intracellular stores is an initial step in hypoxic pulmonary vasoconstriction of rat pulmonary artery resistance vessels. Circulation 1997; 96: 3647-3654.

164 Morio Y, McMurtry IF. $\mathrm{Ca}^{2+}$ release from ryanodine-sensitive store contributes to mechanism of hypoxic vasoconstriction in rat lungs. J Appl Physiol 2002; 92: 527-534.

165 Jabr RI, Toland H, Gelband $\mathrm{CH}$, et al. Prominent role of intracellular $\mathrm{Ca}^{2+}$ release in hypoxic vasoconstriction of canine pulmonary artery. Br J Pharmacol 1997; 122: 21-30.

166 Kang TM, Park MK, Uhm DY. Characterization of hypoxia-induced $\left[\mathrm{Ca}^{2+}\right]_{\mathrm{i}}$ rise in rabbit pulmonary arterial smooth muscle cells. Life Sci 2002; 70: 2321-2333.

167 Dipp M, Nye PC, Evans AM. Hypoxic release of calcium from the sarcoplasmic reticulum of pulmonary artery smooth muscle. Am J Physiol Lung Cell Mol Physiol 2001; 281: L318-L325.

168 Zhang J, Zhou J, Cai L, et al. Extracellular calcium-sensing receptor is critical in hypoxic pulmonary vasoconstriction. Antioxid Redox Signal 2012; 17: 471-484.

169 Aaronson PI. Hypoxic pulmonary vasoconstriction is/is not mediated by increased production of reactive oxygen species. J Appl Physiol 2006; 101: 1000.

170 Shigemori K, Ishizaki T, Matsukawa S, et al. Adenine nucleotides via activation of ATP-sensitive $\mathrm{K}^{+}$channels modulate hypoxic response in rat pulmonary artery. Am J Physiol 1996; 270: L803-L809.

171 Leach RM, Sheehan DW, Chacko VP, et al. Energy state, pH, and vasomotor tone during hypoxia in precontracted pulmonary and femoral arteries. Am J Physiol Lung Cell Mol Physiol 2000; 278: L294-L304.

172 Evans AM, Mustard KJ, Wyatt CN, et al. Does AMP-activated protein kinase couple inhibition of mitochondrial oxidative phosphorylation by hypoxia to calcium signaling in $\mathrm{O}_{2}$-sensing cells? J Biol Chem 2005; 280: 41504-41511.

173 Robertson TP, Mustard KJ, Lewis TH, et al. AMP-activated protein kinase and hypoxic pulmonary vasoconstriction. Eur J Pharmacol 2008; 595: 39-43.

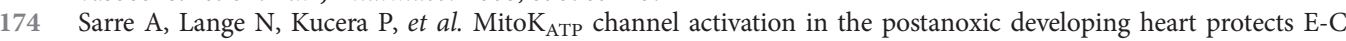
coupling via NO-, ROS-, and PKC-dependent pathways. Am J Physiol Heart Circ Physiol 2005; 288: H1611-H1619.

175 Paddenberg R, Faulhammer P, Goldenberg A, et al. Impact of modulators of mitochondrial ATP-sensitive potassium channel (mitoK ATP $_{\text {) }}$ on hypoxic pulmonary vasoconstriction. Adv Exp Med Biol 2009; 648: 361-368.

$176 \mathrm{Li}$ X, Rapedius M, Baukrowitz T, et al. 5-Hydroxydecanoate and coenzyme A are inhibitors of native sarcolemmal $\mathrm{K}_{\mathrm{ATP}}$ channels in inside-out patches. Biochim Biophys Acta 2010; 1800: 385-391.

177 Olson KR, Deleon ER, Gao Y, et al. Thiosulfate: a readily accessible source of hydrogen sulfide in oxygen sensing. Am J Physiol Regul Integr Comp Physiol 2013; 305: R592-R603.

178 Olson KR, Whitfield NL, Bearden SE, et al. Hypoxic pulmonary vasodilation: a paradigm shift with a hydrogen sulfide mechanism. Am J Physiol Regul Integr Comp Physiol 2010; 298: R51-R60.

179 Skovgaard N, Olson KR. Hydrogen sulfide mediates hypoxic vasoconstriction through a production of mitochondrial ROS in trout gills. Am J Physiol Regul Integr Comp Physiol 2012; 303: R487-R494.

180 Prieto-Lloret J, Shaifta Y, Ward JP, et al. Hypoxic pulmonary vasoconstriction in isolated rat pulmonary arteries is not inhibited by antagonists of $\mathrm{H}_{2} \mathrm{~S}$-synthesizing pathways. J Physiol 2015; 593: 385-401. 